\title{
An overview of patterns and trends in nursing publications from the People's Republic of China
}

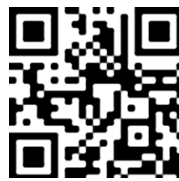

Original article

Fiona Timmins*

School of Nursing and Midwifery, Trinity College Dublin, Dublin D02 T283, Ireland

Received: 15 November 2019; Accepted: 14 December 2019; Published: 20 June 2020

\begin{abstract}
Objective: To explore patterns and trends in nursing publications from the People's Republic of China. Methods: Using the Scopus online database, the author performed two searches in August 2019. The first search identified all items in the category of nursing affiliated to China, and the second search identified publications from China within one specific nursing journal. The author used a theoretical framework to provide a more in-depth understanding of patterns and trends within these items. Results: The number of articles categorized as nursing, with listed authorship in China, within the Scopus database was 17,506. The majority of published papers were categorized as research. Top-ranking Chinese universities, such as Peking University and Fudan University, scored high in terms of several publications listed within the database. Although categorized as nursing, the most common source titles that are mostly high-ranking journals did not feature the high-ranking nursing journals. Identified authors were generally not affiliated with nursing schools. Focused analysis of one of the top-ranking nursing journals, the Journal of Nursing Management, featured top Chinese universities and consistent nursing authorship. Nursing authors were found to have lower $h$-indices than international nursing professors.

Conclusions: There has been a steady increase year by year in publications categorized as nursing from China since 2009, with the majority of published papers categorized as research. There is clear evidence of scholarly activity in nursing in China, both in the published literature and anecdotally in practice. However, nursing scholars need to do more to increase dissemination and ensure that nursing professors are leading and driving nursing research, although in a multidisciplinary context. There is also a need for increased exposure of Chinese nursing scholarship in high-ranking nursing journals.
\end{abstract}

Keywords: nurse $\bullet$ nursing $\bullet$ research $\bullet$ publication $\bullet$ dissemination

(c) Shanxi Medical Periodical Press.

\section{Introduction}

Similar to many countries in the world, nursing has long held a place in the historical fabric of civilization in the People's Republic of China. ${ }^{1}$ At present, there are more than 4 million nurses in China; however, the professionalization of nursing is relatively recent, and similarly to many European countries the past two decades have seen an advancement in educational levels for nurses up to and including $\mathrm{PhD}$. $^{2}$ This positive development for nursing arose after the development of the People's Republic of China, however, the exact number of nurses educated to PhD level is not clear. Professional development is ongoing, with desires for increased

How to cite this article: Timmins F. An overview of patterns and trends in nursing publications from the People's Republic of China. Front Nurs. 2020; 2: 111-118. 
education and specialism in response to rapidly changing health trends, technological advances, and population changes. ${ }^{3}$ Indeed, health care reform, and nurses' key role in this, is high on political agendas in China. ${ }^{4}$

In the reports of the 19th National Congress of the Communist Party of China, Chinese President Xi Jingping pointed out that "people's health is an important symbol of national prosperity and strength". He made a series of important decisions and plans for implementing the healthy China strategy. Nursing staff play an important role in the process of realizing the goal of "meeting the needs of multi-level and diversified health services" in healthy China (p. 373). ${ }^{1}$

Within this context, much is done to strengthen the work environment for nurses. Leadership is key in this regard and Chinese nursing has a big commitment to the growth and development of nursing leadership. The Chinese Nursing Association, for example, hosts an annual National Nursing Management Reform and Innovation Forum with a clear focus on a professionalizing agenda for nurses in China. ${ }^{5}$ Caring is also developing as a key facet of nursing within both educational curricula and clinical practices. ${ }^{5}$ For example, the Chinese Nursing Development Program (2011-2015) recommended that nursing schools increase the humanities content in their curriculum to strengthen caring consciousness. Increasingly, Chinese nursing scholars have been engaging in research in the field of caring and also in other important facets of nursing. ${ }^{5}$ There is also a growing awareness of the need to encourage improved evidence-based practice among nurses, with increasing efforts in this regard ${ }^{6}$ and an increased number of Chinese peer-reviewed journals, with a distinct focus on nursing research.

However, beyond this, there is little systematic understanding of the patterns and trends of research that are published by Chinese nursing scholars. As a result, this article aimed to provide a brief overview of general patterns and trends in publications from China in nursing journals and suggest ways in which this information could be utilized to develop a successful publication pathway for Chinese nurses in the future.

\section{Materials and methods}

\subsection{Materials}

The materials utilized for this analysis were items listed in Scopus. ${ }^{7}$ Scopus is a large international online abstract and citation repository developed by Elsevier and launched in 2004. ${ }^{8}$ This database hosts more than
24,000 active titles from 5,000 publishers, across the life, social, physical, and health sciences, all of which are rigorously scrutinized by an independent review board before selection and later on an annual basis. ${ }^{8}$

\subsection{Methods}

\subsubsection{Scopus metadata architecture}

Using a sophisticated metadata architecture, the Scopus database provides detailed information on each title (e.g., citations), journals, and authors. Scopus data analytics include quality measures for each title such as $h$-index and CiteScore. It has a facility to calculate the authors' $h$-index. It also supports recording of authors' profiles including affiliations, ORCID identification (ID), ${ }^{9}$ number of publications, and details on the number of citations each published document has received.

\subsubsection{Scopus analytics}

Scopus provides a database search engine with both basic and advanced functions. ${ }^{7}$ Due to the "rich metadata" provided for all indexed contents, the users are allowed to conduct precise searches. ${ }^{8}$ The basic search engine permits a "document search" under three categories: documents, authors, or affiliations. ${ }^{7}$ Within these searches, detailed metadata are available to further categorize and limit the search within any of the aforementioned fields. The analytics and search facilities of metadata permit researchers to visualize, compare, and export data to assess research trends. Scopus provides access to graphical displays, charts, and tables, which can be manipulated to view specific parameters. This permits the disclosure of patterns and trends, and new insights that may be easily communicated with others. ${ }^{8}$ Following the initial search, the results can be further broken up into several categories to provide the indepth analysis (e.g., year, source, author, and country or territory). ${ }^{8}$ The following analytics were used in this study:

Analyze search results: This allows a greater understanding of metrics with a visual analysis of search results broken up into seven categories (year, source, author, affiliation, country or territory, document type, and subject area). ${ }^{8}$

Author profile page: This is used to analyze and track an individual's citation history. Using the author profile page, researchers can view an author's total citation and document count, $h$-index, and ORCID record (if available) and access a collection of in-depth and visual analysis tools designed to provide a better picture of an individual's publication history and influence. ${ }^{8}$ 


\subsubsection{Web of Science analytics}

Although Scopus includes a CiteScore within its metrics, ${ }^{8}$ it does not provide information on the more widely accepted impact factor. ${ }^{10,11}$ According to citations captured in the Web of Science ${ }^{12}$ database, the impact factor, as calculated by Clarivate Analytics, is a measure of the average number of times articles from a preceding 2-year time frame have been cited in a subsequent given year. ${ }^{11}$ Impact factor details were included to provide more detailed insight on the results.

\subsubsection{Method of data collection}

The author performed two searches using the Scopus database $^{7}$ in August 2019. The initial search was by affiliation (China) and further categorized this into subject area (nursing). The items isolated from this search ( $n=17,506)$ were then analyzed according to source title (e.g., Journal), affiliation, and author name. Using the author profile page, $h$-indexes and ORCID IDs of the top-cited authors were retrieved.

The author subsequently searched for items according to document type, using the subcategory source title, and isolated all the items from one specific nursing journal, the Journal of Nursing Management ${ }^{13}$ (Table 1). The Journal of Nursing Management is a top-ranking international peer-reviewed journal (Table 1). It is the only title within the top 20 that deals specifically with issues of nursing management (Table 1).

The items isolated from this search $(n=2,266)$ were further categorized into country/territory (China). The items identified ( $n=43)$ were then analyzed according to author name and document type. Using the author profile page, $h$-indexes of the top-cited authors were retrieved. Where the authors did not have a reported ORCID ID, a Scopus Identifier was noted.

To provide a more in-depth understanding of patterns and trends within these 43 items, the author used a theoretical framework. This framework, derived from Weberg et al.'s ${ }^{14}$ outline of the leadership role in nursing (Table 2), provided a template for determining broad categories of the items in terms of the domains of leaderships discussed, described, or analyzed in this article.

\subsubsection{Reliability}

Using the Scopus analytics to analyze patterns and trends is highly reliable insofar as manual data entry was not required, thus reducing the risk, error, or missing data. Scopus is an extensive database with sophisticated analytics. ${ }^{8}$ Its rigorous internal peerreviewed system assures the validity and creditability of the items, which are further re-evaluated every year. ${ }^{8}$

\begin{tabular}{|c|c|c|}
\hline Rank & Full journal title & $\begin{array}{l}\text { Journal impact } \\
\text { factor (2018) }\end{array}$ \\
\hline 1 & $\begin{array}{l}\text { International Journal of Nursing } \\
\text { Studies }\end{array}$ & 3.570 \\
\hline 2 & Journal of Tissue Viability & 2.831 \\
\hline 3 & Journal of Nursing Scholarship & 2.540 \\
\hline 3 & Nursing Outlook & 2.540 \\
\hline 5 & Australian Critical Care & 2.515 \\
\hline 6 & Journal of Cardiovascular Nursing & 2.510 \\
\hline 7 & $\begin{array}{l}\text { Worldviews on Evidence-Based } \\
\text { Nursing }\end{array}$ & 2.500 \\
\hline 8 & $\begin{array}{l}\text { European Journal of Cardiovascular } \\
\text { Nursing }\end{array}$ & 2.497 \\
\hline 9 & Nurse Education Today & 2.442 \\
\hline 10 & $\begin{array}{l}\text { International Journal of Mental Health } \\
\text { Nursing }\end{array}$ & 2.433 \\
\hline 11 & European Journal of Cancer Care & 2.421 \\
\hline 12 & Journal of Nursing Management & 2.386 \\
\hline 13 & Journal of Advanced Nursing & 2.376 \\
\hline 14 & Journal of Human Lactation & 2.349 \\
\hline 15 & Clinical Simulation in Nursing & 2.286 \\
\hline 16 & Birth-Issues in Perinatal Care & 2.129 \\
\hline 17 & Women and Birth & 2.079 \\
\hline 18 & American Journal of Critical Care & 2.063 \\
\hline 19 & Midwifery & 2.048 \\
\hline 20 & Cancer Nursing & 2.022 \\
\hline
\end{tabular}

Source: Web of Science Group. ${ }^{12}$

Table 1. Top-ranking nursing journals 2018.

\begin{tabular}{l}
\hline Domain of nursing leadership \\
\hline \hline Navigating the care networks and creating the context for \\
professional practice \\
Policy, legislation, licensing, and professional nurse roles \\
Staffing, scheduling, and patient care assignments \\
Becoming a professional nurse \\
The person of the leader the capacity to lead \\
Applying the practices of leadership \\
Principles of ethical decision-making \\
Change and innovation \\
Conflict skills for the clinical leader \\
Leadership and practice partnerships \\
Managing your career \\
Resources for healthcare excellence \\
Delegation and supervision \\
Negotiation \\
Accountability and ownership
\end{tabular}

Source: Weberg et al. ${ }^{14}$

Table 2. Weberg et al.'s domains of nursing leadership. 
The analytical capability of Scopus provides the capacity for analysis of international and interdisciplinary patterns and trends, which are not always available in other databases. Comparing a smaller database with the Web of Science, ${ }^{9}$ the smaller database can provide comprehensive and reliable data ${ }^{15,16}$ and it also has a more detailed and sophisticated database search engine compared with that provided by the Web of Science. ${ }^{12}$

Weberg et al.'s ${ }^{14}$ domains of nursing leadership framework (Table 2) were previously pilot-tested for analyzing leadership patterns and trends and provided informative data. ${ }^{17}$ The emerging patterns identified within this pilot testing were largely in keeping the previously identified trends, thus indicating reliability and consistency. ${ }^{17}$ In addition, the general patterns identified in this current study were also largely consistent with previous findings. ${ }^{17}$

\section{Results}

\subsection{Scopus database search by affiliation (China) and subject area (nursing)}

The number of articles categorized as nursing, with listed authorship in China, within the Scopus database was 17,506 . The majority of papers $(86 \%, n=14,973)$ were published in the last 10 years. The number of publications published annually in the last 5 years (2015-2019) was consistently two times higher than the number published in the preceding years, i.e., before 2012 . The articles were most commonly published in the following journals: Chinese Journal of Emergency Medicine ( $n=2,309)$, Journal of the Science of Food and Agriculture $(n=1,436)$, Journal of Functional Foods $(n=991)$, Chinese Journal of Clinical Nutrition $(n=881)$, Nutrients $(n=624)$, and Stroke $(n=600)$. The impact factor, ranking of sources, ${ }^{10}$ and CiteScore ${ }^{7}$ are outlined in Table 3.

The majority of published papers were categorized as research articles $(n=15,271)$, and a few of them were literature reviews $(n=1,303)$. The Chinese scholars published 375 letters during this period and there were very few editorials $(n=70)$. The main affiliations for these publications were the Ministry of Education China $(n=715)$, Peking University $(n=709)$, Capital Medical University China $(n=697)$, Zhejiang University $(n=665)$, Sun Yat-Sen University $(n=631)$, Peking Union Medical College $(n=595)$, Shanghai Jiao Tong University $(n=542)$, Fudan University $(n=515)$, Sichuan University ( $n=491$ ), and Chinese Academy of Sciences $(n=461)$. The author name search revealed the top five authors (those who published most frequently) in the category of "nursing" (Table 4).

\subsection{Scopus database search by source title (Journal of Nursing Management) and affiliation (China)}

There were 43 publications affiliated to China, which were published in the Journal of Nursing Management $^{13}$ (Table 1) since its foundation in 1993. In keeping with general trends in the journal, the majority of these papers were research articles $(95.3 \%, n=41)$, few were literature reviews $(2.3 \%, n=1)$, and no editorials were published. Institutional affiliations most frequently cited were the Hong Kong Polytechnic $(n=4)$, Fudan University $(n=3)$, and Zhengzhou University $(n=3)$. Most other establishments published two papers or less. The number of papers published by a single author was 2 , and 11 authors published these papers. Table 5 provides an example of five of these authors.

\subsection{An analysis using Weberg et al.'s framework of publications affiliated to China published in the Journal of Nursing Management}

In terms of topics, according to Weberg et al.'s ${ }^{14}$ outline of the leadership role in nursing, the main focus of these

\begin{tabular}{|c|c|c|c|}
\hline Journal title & Web of Science categories (ranking) & $\begin{array}{l}\text { Journal impact } \\
\text { factor (2018) }\end{array}$ & $\begin{array}{l}\text { Scopus CiteScore } \\
\text { (2018) }\end{array}$ \\
\hline Stroke & Peripheral Vascular Disease (5th) and Clinical Neurology (20th) & 6.058 & 4.94 \\
\hline Nutrients & Nutrition \& Dietetics (17th) & 4.170 & 4.51 \\
\hline Journal of Functional Foods & Nutrition \& Dietetics (46th) and Food Science \& Technology (33rd) & 3.197 & 3.78 \\
\hline $\begin{array}{l}\text { Journal of the Science of Food and } \\
\text { Agriculture }\end{array}$ & $\begin{array}{l}\text { Agriculture and Multidisciplinary Science (9th); Chemistry and } \\
\text { Applied Science (23rd); and Food Science \& Technology (43rd) }\end{array}$ & 2.422 & 2.75 \\
\hline $\begin{array}{l}\text { Chinese Journal of Emergency } \\
\text { Medicine }\end{array}$ & Not listed & None & 0.05 \\
\hline Chinese Journal of Clinical Nutrition & Not listed & None & 0.05 \\
\hline
\end{tabular}

Sources: Scopus ${ }^{7}$ and Web of Science Group. ${ }^{12}$

Table 3. Impact factor, ranking of sources, and CiteScore (that are cited most frequently) in the category of "nursing" cited in Scopus in August 2019 


\begin{tabular}{|c|c|c|c|c|c|}
\hline Author & Affiliation & Title* & $h$-Index & ORCID ID & $\begin{array}{l}\text { Number of } \\
\text { publications }\end{array}$ \\
\hline $\begin{array}{l}\text { Shek, D.T.L., PhD (HKU), } \\
\text { FHKPS, BBS, SBS, JP }\end{array}$ & $\begin{array}{l}\text { Department of Applied Social } \\
\text { Sciences, Hong Kong Polytechnic } \\
\text { University, Kowloon, Hong Kong }\end{array}$ & $\begin{array}{l}\text { Chair, Professor of Service } \\
\text { Leadership Education }\end{array}$ & 58 & $\begin{array}{l}\text { https://orcid. } \\
\text { org/0000-0003- } \\
\text { 3359-6229 }\end{array}$ & 112 \\
\hline $\begin{array}{l}\text { Li, D., BSc in Medicine, } \\
\text { MSc in Natural Products, } \\
\text { and PhD in Nutrition }\end{array}$ & $\begin{array}{l}\text { Department of Food Science \& } \\
\text { Nutrition, Zhejiang University, } \\
\text { Hangzhou, China }\end{array}$ & Professor of Nutrition & 36 & $\begin{array}{l}\text { https://orcid. } \\
\text { org/0000-0001- } \\
\text { 5227-5565 }\end{array}$ & 93 \\
\hline $\begin{array}{l}\text { Zheng, W., MD, PhD, } \\
\text { MPH }\end{array}$ & $\begin{array}{l}\text { Vanderbilt Ingram Cancer Center, } \\
\text { Department of Medicine, Nashville, } \\
\text { USA }\end{array}$ & $\begin{array}{l}\text { Co-Lead of the Cancer } \\
\text { Epidemiology Research } \\
\text { Program }\end{array}$ & 109 & $\begin{array}{l}\text { https://orcid. } \\
\text { org/0000-0003- } \\
\text { 1226-070X }\end{array}$ & 77 \\
\hline Shu, X.O., MD, PhD & $\begin{array}{l}\text { Vanderbilt University School of } \\
\text { Medicine, Nashville, USA }\end{array}$ & $\begin{array}{l}\text { Ingram Professor of Cancer } \\
\text { Research; Professor of } \\
\text { Medicine/Co-Lead of the } \\
\text { Cancer Epidemiology } \\
\text { Research Program }\end{array}$ & 97 & None & 65 \\
\hline Cai, W. & $\begin{array}{l}\text { Shanghai Jiao Tong University, } \\
\text { Department of Pediatric Surgery, } \\
\text { Shanghai, China; Shanghai } \\
\text { Key Laboratory of Pediatric } \\
\text { Gastroenterology and Nutrition, } \\
\text { Shanghai, China; Shanghai Institute of } \\
\text { Pediatric Research, Shanghai, China }\end{array}$ & Professor of Medicine & 19 & None & 58 \\
\hline
\end{tabular}

Note: "Titles only if available.

Table 4. Top five authors from China (those who published most frequently) in the category of "nursing" cited in Scopus in August 2019.

\begin{tabular}{|c|c|c|c|c|c|c|}
\hline Author & Affiliation & Title & h-Index & $\begin{array}{l}\text { Scopus author } \\
\text { identifier }\end{array}$ & $\begin{array}{l}\text { ORCID } \\
\text { ID }\end{array}$ & $\begin{array}{l}\text { Number of } \\
\text { publications }\end{array}$ \\
\hline $\begin{array}{l}\text { Cheng, L., } \\
\text { MSN, PhD }\end{array}$ & $\begin{array}{l}\text { School of Nursing, Fudan University, } \\
\text { Shanghai, China }\end{array}$ & $\begin{array}{l}\text { School of Nursing, Faculty } \\
\text { Member }\end{array}$ & 4 & 57191886208 & None & 2 \\
\hline$H u, Y$, PhD & $\begin{array}{l}\text { Fudan University, Shanghai, } \\
\text { China and Fudan University, A } \\
\text { Joanna Briggs Institute Centre of } \\
\text { Excellence, Shanghai, China }\end{array}$ & $\begin{array}{l}\text { Professor, School of Nursing, } \\
\text { Fudan University, Shanghai, } \\
\text { China }\end{array}$ & 6 & 56174094600 & None & 2 \\
\hline $\begin{array}{l}\text { Li, Q.J., } \\
\text { PhD, RN }\end{array}$ & $\begin{array}{l}\text { School of Nursing, Harbin Medical } \\
\text { University, Affiliated Hospital \& } \\
\text { College of Nursing, Harbin, China }\end{array}$ & $\begin{array}{l}\text { Professor, The 2nd Affiliated } \\
\text { Hospital \& College of Nursing, } \\
\text { Harbin Medical University, } \\
\text { Harbin, China }\end{array}$ & 5 & 55587486800 & None & 2 \\
\hline $\begin{array}{l}\text { Liu, H., } \\
\text { PhD, RN, } \\
\text { FAAN }\end{array}$ & $\begin{array}{l}\text { Peking Union Medical College, } \\
\text { Chinese Academy of Medical } \\
\text { Sciences, Beijing, China }\end{array}$ & $\begin{array}{l}\text { Dean and Professor; Director } \\
\text { of WHO Collaborating Center } \\
\text { for Nursing Policy-Making and } \\
\text { Quality Management }\end{array}$ & 9 & 50761197600 & None & 2 \\
\hline $\begin{array}{l}\text { LiU, Y.E. } \\
\text { BSN, } \\
\text { MSN, PhD }\end{array}$ & $\begin{array}{l}\text { PLA Stroke Care and Research } \\
\text { Centre, The Second Artillery General } \\
\text { Hospital PLA, Beijing, China }\end{array}$ & Not listed & 4 & 55341814100 & None & 2 \\
\hline
\end{tabular}

Table 5. A selection of five authors from China who published most frequently in the Journal of Nursing Management since 1993 (Scopus 2019 ).

Chinese papers in the Journal of Nursing Management is outlined in Table 6.

\section{Discussion}

Overall, there has been a steady increase year by year in publications categorized as nursing from China since 2009, with the majority of published papers categorized as research. This is a very positive finding given the importance of research and scholarly output about the professional development of nursing as an academic discipline. ${ }^{18}$ This trend may also be consistent with a generalized trend of ongoing strengthening of Chinese universities and educational reform enacted 


\begin{tabular}{ll}
\hline Domain of nursing leadership & $\begin{array}{l}\text { Number of } \\
\text { papers (\%) }\end{array}$ \\
\hline \hline $\begin{array}{l}\text { Navigating the care networks and creating the } \\
\text { context for professional practice }\end{array}$ & $13(30.23 \%)$ \\
Policy, legislation, licensing, and professional nurse & $9(20.93 \%)$ \\
roles & \\
Staffing, scheduling, and patient care assignments & $7(16.27 \%)$ \\
Becoming a professional nurse & $4(9.30 \%)$ \\
The person of the leader the capacity to lead & $4(9.30 \%)$ \\
Applying the practices of leadership & $3(6.97 \%)$ \\
Principles of ethical decision-making & $2(4.65 \%)$ \\
Change and innovation & $1(2.32 \%)$ \\
Conflict skills for the clinical leader & $0(0.00 \%)$ \\
Leadership and practice partnerships & $0(0.00 \%)$ \\
Managing your career & $0(0.00 \%)$ \\
Resources for healthcare excellence & $0(0.00 \%)$ \\
Delegation and supervision & $0(0.00 \%)$ \\
Negotiation & $0(0.00 \%)$ \\
Accountability and ownership & $0(0.00 \%)$ \\
Management (1993-2019) & $43(100 \%)$ \\
\hline
\end{tabular}

Source: Weberg et al. ${ }^{14}$

Table 6. An outline of patterns and trends in papers from the People's Republic of China published in the Journal of Nursing Management according to Weberg et al.'s outline of the leadership role in nursing.

by the Chinese Ministry of Education of the People's Republic of China over the past 25 years. ${ }^{19}$ Indeed, this study revealed that top-ranking Chinese universities ${ }^{19}$ such as Peking University and Fudan University score highly in terms of number of publications listed within the database.

This is an important finding as both Peking and Fudan Universities are ranked in the top five universities in China, and they feature among the best in the world (24th and 109th ranks, respectively). ${ }^{19}$ Government plans to develop Chinese universities into top-class international universities are ongoing, with the recent development of the Double First Class University Plan (2017) to comprehensively develop Chinese universities and individual university departments into world-class universities and disciplines. ${ }^{20}$ Certainly, peer-reviewed publication plays an important role in any such development given its potential contribution to strengthening academic reputation and also the potential for citation and impact, both of which are key features of metrics used to determine university rankings. ${ }^{21}$

It is interesting to note that although categorized as nursing, the most common source titles found in this study did not feature the high-ranking nursing journals (Table 1). However, the majority of the source titles were high-ranking journals except for the two Chinese sources (Table 3). The latter journals did not appear to have an impact factor and Scopus citation scores (CiteScore) indicated with very little citation activity (Table 3 ). However, there is a claim that the impact factor applies mostly to a "disproportionate representation of Western journals (p. 542)."19 At the same time, except for the journal Stroke, there was a little variance between impact factor and Scopus citation scores (CiteScore) across the journals.

A closer examination of the trends also revealed that the top five authors (those who published most frequently) in the category of "nursing" did not appear to be affiliated to nursing schools or a nursing professor. This may be due in part to the limited number of nursing scholars with $\mathrm{PhD},{ }^{2}$ however, a deeper analysis of activity within one specific nursing journal, namely the Journal of Nursing Management ${ }^{15}$ (Table 1), was more insightful and provided a little more information on the publication of Chinese nursing research activity.

As effective leadership and management play an important part both in the development of nursing as a discipline and as a science and in the professionalization of nursing, exploring scholarly output about nursing management provides additional information about nursing scholars' activities. In keeping with general trends in the journal, the majority of these papers were research articles. ${ }^{17}$ However, very few literature reviews and there were no editorials or something that differs from the usual pattern of publication in this journal. ${ }^{17}$ Again a top-ranking university (Fudan University ${ }^{17}$ ) featured highly. Of note, the $h$-indexes of Chinese scholars appeared modest compared with an average $h$-index of 12 among international nursing professors, ${ }^{22}$ and none had been listed in ORCID ID. ${ }^{9}$

In terms of topics (according to Weberg et al.'s ${ }^{14}$ outline of the leadership role in nursing), two of the main foci of these Chinese papers in the Journal of Nursing Management were navigating care networks/creating the context for professional practice and staffing, scheduling, and patient care assignments (Table 6). This is consistent with the general patterns and trends of publication in the journal. ${ }^{17}$ However, a particular focus in the publications on policy, legislation, licensing, and professional nurse roles, becoming a professional nurse and principles of ethical decision-making (Table 5), revealed higher than usual trends. Overall 15 papers were published on these topics, accounting for more than onethird of all papers arising from China. These are areas that receive limited attention overall in the Journal with less than one quarter $(n=145)$ of all papers published in the last 5 years in the Journal dedicated to these topics. ${ }^{17}$ However, only one paper was observed to have dealt with change and innovation, a feature that is less prominent than overall patterns in the Journal 
where $>7 \%$ of papers dedicated to this topic. ${ }^{17}$ Areas that are replete of publications (delegation and supervision, negotiation, and accountability and ownership) are not addressed frequently in the journal. ${ }^{17}$ However, the absence of papers in the fields of leadership and practice partnerships, and managing your career and resources for health care excellence certainly would receive more attention in the Journal overall and are likely areas that could be developed more in the future. ${ }^{17}$

\section{Conclusions}

China, similar to the rest of the countries in the world, is facing unprecedented demographic and technological changes for the future. The consistently changing nature of health care requires a skilled workforce who can provide evidence-based practice. Nurses are required to understand and use research, and fundamentally nursing scholars ought to be leading and driving research and evidence-based practice in the field. ${ }^{23,24}$ There is clear evidence of scholarly activity in nursing in China, both in the published literature and anecdotally in practice. However, nursing scholars need to do more to increase dissemination and ensure that nursing professors are leading and driving nursing research, ${ }^{18}$ albeit in a multidisciplinary context. There is also a need for increased exposure of Chinese nursing scholarship in high-ranking nursing journals. Ongoing governmental activity ${ }^{20}$ will likely support capacity building within the nursing profession, and targeted efforts to accelerate PhD numbers among nurses and publication would likely have a positive influence on the impact of the profession internationally. ${ }^{18}$ Nursing scholars can also contribute to raising their profile by registering for an ORCID $\mathrm{ID}^{9}$ that can be linked to their work. This is especially useful to identify single researchers where there are similarities in names or where there are changes in affiliation or names/titles.

The large population in China makes it an exceptional forum for research and development, particularly in the field of nursing management. Researchers ought to continue to focus on their strengths about policy, legislation, licensing, and professional nurse roles, becoming a professional nurse and principles of ethical decision-making, and they also seek to research in areas such as delegation and supervision, negotiation, accountability and ownership leadership, and practice partnerships and managing your career and resources for healthcare excellence to address current gaps. In China, patients and staff numbers in hospitals can be up to (and sometimes more than) 10 times the size of those in the UK or USA, rendering a remarkable opportunity for nursing research and especially for the understanding, application, and evaluation of nursing management. The numbers of staff on duty per clinical area far outweigh many hospitals internationally and thus offer a unique and valuable insight into patient care and management. Although journal citations have a rich contribution to the measurement of quality of scholarship $^{11,15,16}$ and are therefore an important component of building excellence in terms of university rankings, ${ }^{21}$ the potential bias of database repositories toward Western journals could likely negatively impact on perceptions of quality research. Additional measures to support Chinese scholars to publish peer-reviewed publications within these high-ranking journals are needed and the number of Chinese journals currently listed needs to be increased. However, English is considered the "language of health science," 23 thus English as a second language may be a barrier for Chinese scholars $^{5}$ and resources and investment in translation and publication support are likely to be a requirement for facilitating future success in addition to other capacity-building measures.

\section{Limitations}

A single author collected the data. However, both Scopus and Web of Science analytics are comprehensive and reliable, cross-checking of individual results was not required. Furthermore, given the level of sophistication of these analytical tools manual cross-checking would not be feasible. The analysis of patterns and trends using Weberg et al.'s framework, ${ }^{5}$ although consistent with other trends, ${ }^{17}$ could have benefited from cross-checking in terms of reliability. However, the purpose of this phase of the research was exploratory. It was largely for information purposes to provide broad guidance to authors and editors regarding patterns and trends, potential information, and gaps in the published research. Absolute reliability with regard to emerging trends was not required.

The broad categorization of journals within the category of nursing with the Scopus database ${ }^{7}$ limits the generalizability of the findings. Furthermore, while the overarching findings of the first phase of this research were interesting in terms of the patterns and trends that emerge, it is difficult to have full confidence in the findings in terms of an accurate picture of nursing scholarship in China, given the broad conceptualization of nursing within the database.

Although the majority of data presented were largely reliable, it might be useful for analytics to support greater thematic analysis within journals for the future, and the categorization of nursing within Scopus would benefit as it is more focused on nursing-specific journals. 


\section{Ethical approval}

Ethical issues are not involved in this paper.

\section{References}

1. Mu JY, Yao YT, Cui WY, Han DY, Yang L. A Brief Analysis of the Historical Origin and Development of Nursing. 2018 International Conference on Education, Management and Social Science (EMSS 2018); 2018. ISBN: 978-1-60595-554-4. www.dpiproceedings.com/index.php/dtssehs/article/download/24094/23729. Accessed May 31, 2019.

2. Kalisch BJ, Liu YL. Comparison of nursing: China and the United States. Nurs Econ. 2009;27: 322-331.

3. World Health Organization. China Country Assessment Report on Ageing and Health. Geneva, Switzerland: WHO; 2015. https://www.who.int/ageing/publications/china-country-assessment/en/ Accessed May 31, 2019.

4. Fang PQ. Green Book of Health Reform and Development 2015. Focus on Public Hospitals' Reform and Development. Beijing, China: People's Publishing House; 2015 (in Chinese).

5. Liu YL, Wu XJ, Timmins F. Strengthening actions for caring as a core component of nursing in the People's Republic of China. J Nurs Manage. 2019;27:1576-1579.

6. He MX, Hu Y. Integrating the online nursing evidence-based information resources for evidence-based nursing study in China. Int $J$ Nurs Pract. 2012;18:429-436.

7. Scopus. https://www.scopus.com/home.uri. Accessed July 27, 2019.

8. Elsevier. https://www.elsevier.com/solutions/scopus. Accessed November 9, 2019.

9. ORCID. https://orcid.org/register. Accessed November 9, 2019.

10. Lahiry S, Sinha R, Thakur S. Impact factor: Does it really have an impact? Indian J Dermatol Venereol Leprol. 2019;85:41-545.

11. American Psychological Association. https://www. apa.org/pubs/journals/resources/impact-factors. Accessed November 9, 2019.

12. Web of Science Group. https://clarivate.com/webofsciencegroup/solutions/web-of-science/. Accessed November 9, 2019.

\section{Conflicts of interest}

There is no conflict of interest.
13. Wiley. https://onlinelibrary.wiley.com/journal/13652834. Accessed November 9, 2019.

14. Weberg D, Mangold K, Porter-O'Grady T, Malloch K. Leadership in Nursing Practice. 3rd ed. Burlington, USA: Jones \& Bartlett Publishers; 2018.

15. Yang K, Meho LI Citation analysis: a comparison of Google Scholar, Scopus, and Web of Science. Proc Am Soc Inf Sci Technol. 2007;43:1-15.

16. Kulkarni AV, Aziz B, Shams I, Busse JW. Comparisons of citations in Web of Science, Scopus, and Google Scholar for articles published in general medical journals. JAMA. 2009;302:1092-1096.

17. Timmins F. An overview of 5-year patterns and trends in the Journal of Nursing Management. J Nurs Manage. 2019;28:457-460.

18. Begley C, McCarron M, Huntley-Moore S, Condell $S$, Higgins A. Successful research capacity building in academic nursing and midwifery in Ireland: an exemplar. Nurse Educ Today. 2014;34:754-760.

19. Times Higher Education. https://www.timeshighereducation.com/student/best-universities/best-universities-china. Accessed November 9, 2019.

20. International Education. https://internationaleducation.gov.au/News/Latest-News/Pages/ Implementation-measures-released-for-China'snew-world-class-university-policy.aspx. Accessed November 9, 2019.

21. Top Universities. https://www.topuniversities. com/qs-world-university-rankings/methodology. Accessed November 9, 2019.

22. Watson R, McDonagh R, Thompson DR. H-indices: an update on the performance of professors in nursing in the UK. J Adv Nurs. 2017;73:999-1001.

23. Sasso L, Watson R, Barisone M, et al. The contribution of nursing doctoral schools to the development of evidence 10 years after their establishment in Italy: an exploratory descriptive survey of former and current doctoral students' publications. Nurs Open. 2019;6:745-753.

24. Bressan V, Bagnasco A, Bianchi M, et al. Barriers to research awareness among nurses in Italy. $J$ Nurs Manage. 2017;25:243-245. 